This item was submitted to Loughborough's Research Repository by the author.

Items in Figshare are protected by copyright, with all rights reserved, unless otherwise indicated.

\title{
(Re)examining the effects of athlete brand image (ABI) on psychological commitment: an empirical investigation using structural equation modelling (SEM) and fuzzy set qualitative comparative analysis (fsQCA)
}

\section{PLEASE CITE THE PUBLISHED VERSION}

https://doi.org/10.1080/16184742.2018.1508242

\section{PUBLISHER}

(c) European Association for Sport Management. Published by Taylor and Francis

\section{VERSION}

AM (Accepted Manuscript)

\section{PUBLISHER STATEMENT}

This is an Accepted Manuscript of an article published by Taylor \& Francis in European Sport Management Quarterly on 15 Aug 2018, available online: https://doi.org/10.1080/16184742.2018.1508242.

\section{LICENCE}

CC BY-NC-ND 4.0

\section{REPOSITORY RECORD}

Vaatainen, Merituuli, and Peter Dickenson. 2018. "(re)examining the Effects of Athlete Brand Image (ABI) on Psychological Commitment: An Empirical Investigation Using Structural Equation Modelling (SEM) and Fuzzy Set Qualitative Comparative Analysis (fsqca)". figshare. https://hdl.handle.net/2134/34187. 
(Re)examining the effects of Athlete Brand Image (ABI) on psychological commitment: An empirical investigation using structural equation modelling (SEM) and fuzzy set qualitative comparative analysis (fsQCA)

\begin{abstract}
Research question: How does Athlete Brand Image (ABI) affect psychological commitment (PC) when operationalised at the dimension- (attribute-) level, and measured using reflective indicators? Previous studies operationalise ABI at a higher-order construct level, and/or measure ABI using formative measures. Such operationalisations obscure potentially different relationships between ABI's image attributes and PC.
\end{abstract}

Research methods: A questionnaire was used to collect data from 197 UK respondents over a six-day period within two weeks of the Rio 2016 Olympics concluding. Data were analysed through structural equation modelling (SEM) and fuzzy set Qualitative Comparative Analysis (fsQCA) techniques.

Results and findings: Through SEM, the ABI attributes, athletic expertise, life story, role model, and competition style are positively related to PC, sportsmanship and symbol are negatively related, and rivalry, physical attractiveness, body fit, and relationship effort are nonsignificantly related. Many structural paths between ABI's attributes and PC are also significantly different. Through fsQCA, high PC exists under three complex ABI attribute configurations, while it is absent under four complex configurations.

Implications: Theoretically, finding different relationships between ABI's attributes and PC highlights why operationalising $\mathrm{ABI}$ at the dimension-level provides a more in-depth 
understanding of athlete brand image's effects on PC. Managerially, the findings suggest athletes need only a subset of ABI attributes for high PC. Subsequently, managers can moreefficiently and effectively direct resources towards those attributes that best-capitalise on athletes' images.

Keywords: Athlete Brand Image (ABI); operationalisation; structural equation modelling (SEM); fuzzy set Qualitative Comparative Analysis ( $\left.f_{S} Q C A\right)$; reflective measurement 


\section{Introduction}

The professional sports arena is an intensely commercial industry, where competition from rivals (other athletes/clubs and other forms of entertainment) for audience viewing and spending is fierce (Ross, 2007). In this context, branding - the process by which organisations distinguish themselves from competition - plays an increasingly key role in sport management (Tsiotsou, Alexandris, \& Cornwell, 2014), because it helps organisations stand-out from the crowd. Indeed, both academic and practitioner attention towards branding strategies 'is warranted as customer participation and loyalty are vital at nearly every level of professional sport' (Pifer, Mak, Bae, \& Zhang, 2015, p.88). One way organisations brand themselves is through promoting professional athletes (Carlson \& Donavan, 2013). Professional athletes are among the most valuable assets sport organisations have (Hodge \& Walker, 2015), and are considered popular cultural products (Summers \& Morgan, 2008) that can be branded in their own right (Thomson, 2006). Thus, in the highly competitive industry that is sport, managing athletes' brands is becoming an essential task in enhancing both athletes' (Arai, Ko, \& Kaplanidou, 2013), and sport organisations' (Gladden \& Funk, 2002) marketing value.

Athlete brand management is a relatively new field of academic research, which has received little attention to date (Hodge \& Walker, 2015). Brand management typically aims to create, develop or enhance brand image (Park, Jaworski, \& MacInnis, 1986). Within this context, athlete brand image ( $\mathrm{ABI})$, defined as people's perceptions of athlete brand attributes (Arai, Ko, \& Ross, 2014), purportedly drives consumers' attitudes towards athlete brand extensions (Walsh \& Williams, 2017), identification with athletes' teams (Carlson \& Donavan, 2013), event and merchandise consumption (Braunstein \& Zhang, 2005), loyalty towards endorsed firms (Bush, Martin, \& Bush, 2004), donation intentions towards athletes' causes (Kim \& Walker, 2013) and psychological commitment (PC) towards athlete brands 
(Arai et al., 2013). The ABI-PC relationship is particularly noteworthy because it suggests ABI affects athletes' marketing value through psychological commitment. That is, $\mathrm{PC}$ is generically linked to a brand's value (e.g. its unit price, marketing costs, and number of units sold) (Park, MacInnis, \& Priester, 2014). Within athlete brand contexts, PC is connected to people's attitudes towards athletes (see Sassenberg, 2015), which is itself positively related to people's behavioural responses (e.g. following/purchasing) towards both athletes and athleteendorsed products (cf. Lee \& Park, 2014; McCormick, 2018).

Despite ABI's reported effects on consumers, scant literature explicitly focuses on the ABI construct (Arai et al., 2013). Arai and colleagues $(2013 ; 2014)$ provide a first understanding of brand image of athletes, and propose a measurement instrument to capture ABI, including ten attributes. While some of these attributes (namely athletic expertise, rivalry, physical attractiveness, life story, and role model) are found in team contexts (Gladden \& Funk, 2001; 2002; Ross, James, and Vargas, 2006), five athlete-specific attributes were also identified (namely, sportsmanship, competition style, symbol, body fit, and relationship effort). In turn, and following image-literature convention (e.g. Bachleda, Fakhar, \& Elouazzani, 2016; Kunkel, Funk, \& Lock, 2017), Arai and colleagues treated ABI as one, higher-order construct (that was subsequently linked to PC). However, recent classical measurement theory submits that multi-faceted constructs should be operationalised at the dimension-level, rather than at the higher-order construct-level: 'This approach is conceptually clean, and potentially adds richness to the research model' (Lee \& Cadogan, 2013, p. 246). Hence, it appears our understanding of the ABI-PC relationship would be richer and more fine-grained if we operationalised $\mathrm{ABI}$ at its dimension (attribute) level, as specific and potentially different relationships between each ABI dimension and PC may emerge (e.g. it could be sportsmanship and role model are more strongly-related to PC than physical attractiveness, a finding that would not be identified with a holistic ABI measure). 
Hence, this study's key research objective is to examine ABI's effects on psychological commitment towards an athlete when $\mathrm{ABI}$ is operationalised at the dimension-level.

Second, and given our limited knowledge of ABI's effects at the dimension-level, little is known about which ABI attribute combinations produce high PC. In team contexts, off-field attributes have an especially large impact on team commitment (cf. Bauer, Stokburger-Sauer, \& Exler, 2008). Yet, it is unknown whether this holds for athlete contexts too. In practice, it is likely different $\mathrm{ABI}$ attribute combinations are equivalently relevant for PC because '(a) outcomes of interest rarely have any single cause, (b) causes rarely operate in isolation from each other, and (c) a specific causal attribute may have different and even opposite effects depending on context' (Greckhamer, Misangyi, Elms, \& Lacey, 2008, p. 697). Hence, one subset of ABI attributes may be as important for PC as another subset, or certain $\mathrm{ABI}$ attributes may be beneficial on some occasions but detrimental on other occasions. Traditional regression-based analyses such as structural equation modelling (SEM) cannot examine such possibilities because their foundations are built on examining each antecedent's relationship with an outcome after other antecedents are controlled for (Woodside, 2013).

Conversely, qualitative comparative analysis (QCA) has different epistemological foundations. QCA is a partially inductive-oriented approach (Marx \& van Hootegem, 2007) which attempts to explain whether configurations of causal conditions are necessary or sufficient for an outcome to occur (Vis, 2012): 'Necessary conditions are simple or complex causal recipes that are found in all instances of the outcome occurring; sufficiency conditions, however, are those conditions wherever they occur, the outcome is present and when the sufficiency condition does not occur, instances of the outcome condition both occur and do not occur' (Chang, Tseng, \& Woodside, 2013, p. 96). 
QCA's use within sport management (e.g. Clausen et al., 2018; Lucidarme, Cardon, \& Willem, 2016; Winand, Rihoux, Robinson, \& Zintz, 2013) and general brand settings (e.g. Mühlbacher, Raies, Grohs, \& Koll, 2016) is growing but its use within ABI contexts is conspicuous by its absence. Yet, QCA seems pertinent to ABI contexts, given athletes are unlikely to concurrently possess all image attributes. That is, QCA can unearth whether or when $\mathrm{ABI}$ attributes are beneficial, detrimental or irrelevant to PC, when considered in conjunction with other ABI attributes. Hence, this study's second objective is to uncover different ABI attribute configurations that lead to high PC.

In achieving these objectives, two main theoretical contributions are made. First, through SEM, we demonstrate not all ABI attributes significantly relate to people's PC towards an athlete, and that, importantly, some are negatively related to PC. Significant differences also exist between many of these attributes' path-strengths. Such findings are not apparent if ABI is operationalised (and analysed) at its construct level. Second, through QCA, we demonstrate different bundles of $\mathrm{ABI}$ attributes produce equifinal routes to high $\mathrm{PC}$. Moreover, minor variations in the composition of $\mathrm{ABI}$ attributes are the difference between high PC's presence and absence. Together, the complementarity of SEM's and QCA's findings is an additional contribution to sport management. That is, SEM enables researchers to examine relationship strengths between variables, while QCA allows researchers to observe different configurations of the same variables that lead to a specific outcome (Urueña \& Hidalgo, 2016). Thus, despite differing epistemological foundations, the 'pragmatic scholar might argue that these differences...shed a distinct but hopefully complementary light on the research topic at hand' (Vis, 2012, p. 175). Subsequently, a more-rounded understanding of the linkages between ABI and PC materialises. Managerially, the results suggest athletes' representatives (e.g. agents and managers) should focus their resources on a 
subset of $\mathrm{ABI}$ attributes if high $\mathrm{PC}$ is to materialise, rather than unnecessarily wasting resources trying to enhance (perceptions of) all $\mathrm{ABI}$ attributes.

The remainder of this paper is as follows. First, literature pertaining to operationalising 'image' in sport management is outlined, and subsequently applied to athlete brand image (ABI). Next, apposite psychological commitment literature is offered. Following this, our study's methodology is summarised before our SEM results are produced. We then introduce our specific QCA approach before presenting these findings. A general discussion then precedes managerial implications and theoretical contributions. The paper concludes with limitations highlighting future research directions.

\section{Literature Review}

\section{Operationalising Image in Sport Management}

Operationalisation is defined as 'the transition from theory to measurement' (Hui \& Triandis, 1985, p. 134). In this context, two operationalisation decisions need further review. First, sport management scholars model 'image' as either a single, first-order (e.g. Lohneiss \& Hill, 2014), or as a higher-order (e.g. Gladden \& Funk, 2002), construct. Second, sport management scholars measure 'image' as reflective (e.g. Gladden \& Funk, 2001), formative (e.g. Kunkel et al., 2017), or both reflective and formative (e.g. Braunstein \& Zhang, 2005) in nature. Often, scholars intertwine these two operationalisation decisions. For instance, when operationalising second-order constructs, scholars historically judged ‘(a) a first-order construct can have either formative or reflective indicators, and (b) those first-order constructs can, themselves, be either formative or reflective indicators of an underlying second-order construct' (Jarvis, MacKenzie, \& Podsakoff, 2003, p. 204). Subsequently, 
researchers measured their respective constructs following this viewpoint. However, recent literature has cast doubt on such positions. First,

'[a] higher-order measurement model that is truly unidimensional and conforms to the reflective measurement model is entirely redundant. As a result, unidimensional higher-order measurement models should be modelled as firstorder measurement models. [Meanwhile, if] a higher-order measurement model is not unidimensional... the lower-order constructs should be treated as separate variables...', because they may have different antecedents and outcomes (Lee \& Cadogan, 2013, p. 246).

This suggests ABI should be modelled at the first-order (dimension) level. Conversely, Arai and colleagues $(2013 ; 2014)$ grouped together the on-field attributes athletic expertise (defined as an athlete's achievement and athletic capability), competition style (specific characteristics of an athlete's performance in a competition), rivalry (an athlete's competitive relationship with other athletes), and sportsmanship (an athlete's virtuous behaviour in terms of respect for the game, opponents, and teammates) to produce the higherorder factor, 'athletic performance'; while the off-field attributes physical attractiveness (an athlete's physical qualities and characteristics that spectators find aesthetically pleasing), symbol (an athlete's attractive personal style or fashion), and body fit (how physically fit an athlete is for his or her sport) made up the higher-order factor, 'attractive appearance', and life story (the extent to which an athlete has an appealing, interesting off-field life story), role model (an athlete's ethical behaviour that society has determined is worth emulating) and relationship effort (an athlete's positive attitude toward interaction with fans, spectators, sponsors and media) produced the higher-order factor, "marketable lifestyle' ${ }^{1}$. These three higher-order factors then produced 'athlete brand image' (that linked to PC). Consequently,

\footnotetext{
${ }^{1}$ Arai and colleagues name the ten attributes, 'subdimensions', and the three higher order factors, 'dimensions'.
} 
Arai et al. (2013) may have masked potentially different relationships between ABI's attributes and PC.

Second, formative measurement is labelled a fallacy (Edwards, 2011) because researchers cannot know how formative (latent) variables vary (Lee \& Cadogan, 2013). Indeed, ontologically-speaking, 'the only plausible notion of measurement is a realist one, which assumes the existence of real attributes that cause variation in measurement devices' i.e. reflective measurement (Lee \& Chamberlain 2016, p 106). Hence, irrespective of researchers' (reflective or formative) modelling approaches, measurement theory asserts measurement can only be reflective in nature (Markus \& Borsboom, 2013) so researchers should use reflective indicators wherever possible (Lee \& Chamberlain 2016). It appears ABI's respective dimensions should be measured accordingly. However, some of Arai and colleagues' original items suggest formative indicators. For example, two of Arai et al.'s (2013) original competition style scale items appear to capture 'distinctiveness' ('The athlete's competition style is distinctive from other players') and 'excitement' ('The athlete's competition style is exciting to watch'). Clearly 'distinctiveness' and 'excitement' are not reflective of a unidimensional measure. Again, this raises questions concerning the link between ABI's attributes and PC.

\section{Psychological Commitment (PC)}

According to Mahony, Madrigal, \& Howard (2000), psychological commitment (PC) reflects consumers' attitudinal loyalty, which subsequently predicts behavioural loyalty. Hence, PC is linked to current and future consumption behaviours (Park et al., 2014). Within sport and recreational settings, $\mathrm{PC}$ is associated with people's ongoing attraction to a particular sport (e.g. Bee \& Havitz, 2010), which is manifested in, for example, continued sport event 
attendance, season ticket procurement, and higher levels of sports participation (see e.g. Inoue, Funk, \& McDonald, 2017; Tokuyama \& Greenwell, 2011). Similarly, PC helps explain people's resistance to changing recreational agencies (e.g. Iwasaki \& Havitz, 2004). Consequently, capturing PC is particularly useful for marketers because it helps segment markets and facilitate predictions about individuals' behaviours (e.g. Mahony et al., 2000).

\section{Study Overview}

The Athlete Brand Image Construct

In light of the above discussion, this study investigates how $\mathrm{ABI}$ affects $\mathrm{PC}$ when $\mathrm{ABI}$ is operationalised at the dimension (attribute) level and measured using reflective indicators. We also consider whether the ten $\mathrm{ABI}$ attribute path-strengths are significantly different to each other. We use Arai and colleagues' (Arai et al., 2013; Arai et al., 2014) ABI construct because their conceptualisation provides 'the first comprehensive conceptual framework of athlete brand image' (Arai et al., 2014, p. 97), implying the construct is seminal to future ABI literature. Meanwhile, we capture PC because (a) of its connection to athletes' marketing values and (b) it allows us to contrast our ABI-PC findings against Arai et al. (2013) - if divergent results materialise we begin to demonstrate how operationalising $\mathrm{ABI}$ at the dimension-level can provide richer and more fine-grained knowledge. Figure I outlines the conceptual framework.

FIGURE I ABOUT HERE

\section{Methodology}


For comparison purposes, we closely follow Arai et al.'s (2013) research design as far as possible. First, we purposively selected a number of high-profile athletes to include in the questionnaire: Andy Murray (tennis), Mohamed Farah (track), Jessica Ennis-Hill (track), Laura Trott (cycling), Jason Kenny (cycling), and Nicola Adams (boxing) were chosen because they had each won at least one gold medal during the London 2012 Olympics, meaning they received substantial media attention in their home-country during the build-up, and throughout, the Rio 2016 Olympics. Further, each athlete won at least a silver medal during the Rio 2016 Olympics, ensuring media coverage continued after the Games had finished (when data collection commenced). This media coverage provided a plethora of opportunities for the public to create and reinforce perceptions of athlete brand attributes. Winning medals at two Olympic Games also meant these athletes demonstrated 'a sustained level of consistently superior athletic performance', meaning they are more likely to be product endorsers or spokespeople than less established athletes (Stone, Joseph, \& Jones, 2003, p. 96). Consequently, any findings should have enhanced ecological validity. In line with Arai et al. (2013), respondents answered ABI questions on the athlete they were most familiar with.

Wherever possible, the ten image attribute measures came from Arai et al. (2013). However, whenever Arai and colleague did not use reflective indicators we followed their definitions to find related and established literature to ensure our dimensions were captured with reflective indicators. This approach aligns with the original scholars, who suggested their scale needed further modification and improvement (Arai et al., 2013). Seven-point Likert-type scales captured responses for all constructs. Table I outlines the retained scale items.

TABLE I ABOUT HERE 
Protocol and debriefing analysis with five university students unaware of the study's motivation ensured the research instrument was comprehensible. Data were collected from 197 UK respondents over a six-day period within two weeks of the Rio 2016 Olympic Games concluding. The total response-rate was $67.2 \%$ (54.3\% males, $43.1 \%$ female, $2.5 \%$ did not/preferred to not answer; mean age $=29.4$ years, s.d. $=11.2$ years). $56.9 \%$ of respondents identified tennis star, Andy Murray, as the most familiar athlete, followed by Mohamed Farah (18.3\%), Jessica Ennis-Hill (15.2\%), Laura Trott (4.6\%), Jason Kenny (4.1\%), and Nicola Adams (1.0\%). Potential common method variance (CMV) concerns were alleviated via procedures outlined in Podsakoff, Mackenzie, Lee, \& Podsakoff (2003). Procedurally, respondents were informed that there were no right or wrong answers, that responses were anonymous, and that they should answer questions as honestly as possible. Statistically, a structural model unmeasured latent method factor test was nonsignificant $\left(\Delta \chi^{2}(33)=41.472\right)$, and no relationships changed. Hence, CMV is of little-to-no concern.

\section{Structural equation modelling}

Data were analysed using Lisrel 8.71, which took measurement error into account. Following standard theory-trimming procedures, confirmatory factor analysis (CFA) suggested the model fitted the data well overall: $\chi^{2}(409)=556.197, \mathrm{RMSEA}=.0372, \mathrm{SRMR}=.0530$, with GFI, NNFI and CFI all reaching or exceeding .9 (factor loadings and error variances are found in Table I). Meanwhile, construct reliabilities ranged from .80 to .95 . Finally, average variances extracted (AVEs) ranged from .568 to .861 , while the square root of the lowest AVE (.753, life story) was higher than the highest correlation (.639, between athletic expertise and sportsmanship). Thus, discriminant validity is considered upheld (Fornell \& Larcker, 1981). 
Next, SEM assessed structural paths from each of the ten ABI dimensions to PC. This effectively produced a saturated structural model (i.e. one where all paths are assumed to be nonzero), and thus is equivalent to a CFA with identical fit indices (Williams \& O'Boyle, 2011). Structural path analysis indicates the standardised paths of athletic expertise $(\gamma=.295$, $p=.005)$, life story $(\gamma=.489, p<.001)$, and role model $(\gamma=.279, p=.008)$ are each significantly and positively related to $\mathrm{PC}$, while competition style $(\gamma=.135, p=.084)$ is marginally significant and positively related to PC. Conversely, sportsmanship $(\gamma=-.262, p=.026)$ is significantly and negatively related to PC, while symbol $(\gamma=-.146, p=.096)$ is marginally significant and negatively related to PC. Finally, rivalry $(\gamma=-.001, p=.986)$, physical attractiveness $(\gamma=.058, p=.512)$, body fit $(\gamma=-.005, p=.951)$, and relationship effort $(\gamma=.067$, $p=.425)$ are nonsignificantly related to PC (all two-tailed).

To test whether significant differences exist between any of the ten attribute-paths to PC, we examined the significance of $\Delta \chi^{2}$ ( $\Delta 1$ degree of freedom) when the two paths under investigation were constrained to be equal and remaining paths were fixed to their original regression-path estimates. Using a Bonferroni-corrected $\alpha$-level of .001 (calculated by dividing the traditional $.05 \alpha$-level by 45 observations), results suggest the path from (a) life story to $\mathrm{PC}$ is significantly different from the paths of physical attractiveness $\left(\Delta \chi^{2}=17.846\right)$, rivalry $\left(\Delta \chi^{2}=21.723\right)$, sportsmanship $\left(\Delta \chi^{2}=36.415\right)$, symbol $\left(\Delta \chi^{2}=20.755\right)$, and body fitness $\left(\Delta \chi^{2}=14.681\right)$; (b) athletic expertise to PC is significantly different from the paths of physical attractiveness $\left(\Delta \chi^{2}=15.029\right)$, rivalry $\left(\Delta \chi^{2}=12.801\right)$, sportsmanship $\left(\Delta \chi^{2}=10.812\right)$, and symbol $\left(\Delta \chi^{2}=24.083\right)$; (c) role model to PC is significantly different from the paths of symbol $\left(\Delta \chi^{2}=15.417\right)$ and sportsmanship $\left(\Delta \chi^{2}=15.894\right)$, and (d) sportsmanship to PC is also significantly different from the paths of physical attractiveness $\left(\Delta \chi^{2}=12.056\right)$ and competition style $\left(\Delta \chi^{2}=13.289\right)$. The structural model explains $44.1 \%$ of PC. 
The SEM results suggest when ABI is operationalised as ten separate dimensions not all of ABI's attributes are positively - or even significantly - related to PC. This is in sharp contrast to Arai et al. (2013) who treated ABI as one higher-order construct. Moreover, a number of dimensions have significantly different path-strengths to PC. Finally, and unlike team contexts (e.g. Bauer et al., 2008), the findings indicate some off-field attributes (in this case physical attractiveness, body fit, and relationship effort) may not be important for commitment by themselves. In conclusion, the results illustrate the importance of analysing $\mathrm{ABI}$ at the dimension-level.

That said, it is imprudent to disregard nonsignificant ABI dimension paths, especially as some of these attributes originate from Arai et al.'s (2013) inductive word-elicitation task. This exercise brought-to-mind people's most salient athlete attributes, suggesting these attributes are important for people's PC towards athletes. Moreover, the highest correlation between variables was below 0.70 , implying asymmetric relations exist, and different configurations of independent variables may produce the same outcome (Urueña \& Hidalgo, 2016). Hence, a more judicious approach is to assume each of the ten dimensions is important for PC under certain qualitatively-different circumstances. Pertinent to this paper, we suspect different ABI dimension subsets link to PC. Qualitative Comparative Analysis (QCA) enables us to investigate this possibility.

\section{Qualitative Comparative Analysis (QCA)}

Qualitative Comparative Analysis (QCA) is historically a qualitatively-rooted approach but survey and/or purely quantitative data are increasingly analysed through QCA techniques (see Wagemann, Buche, \& Siewert, 2016). QCA is built on set-theoretic methods, which (a) work with membership scores of cases in sets, (b) perceive relations between social 
phenomena as set relations, and (c) interpret relations in terms of necessary and sufficiency conditions (Schneider \& Wagemann, 2013). Simple conditions (also known as configurations, causes, solutions or recipes) are analogous to independent, singular antecedents in SEM whereas complex conditions involve examining two or more antecedents together (Woodside, 2015). In this context, a single ABI dimension is a simple configuration while complex configurations incorporate two or more ABI dimensions.

Two main QCA techniques exist ${ }^{2}$ : crisp set QCA (csQCA) and fuzzy set QCA (fsQCA). csQCA regards cases are either full members or full non-members of a set, while fsQCA assumes membership gradation. For example, cases can be completely in, more in than out, neither in nor out, more out than in, or completely out of a set (Schneider \& Wagemann, 2013). Theoretically, these 'fuzzy’ qualitative breakpoints avoid unnecessary information-loss which would otherwise occur if data were regarded as only 'in' or 'out' of a set (Tóth, Thiesbrummel, Henneberg, \& Naudé, 2015). In practical terms, we captured people's responses using 7-point Likert-type scales, which 'let respondents make qualitative statements of agreement, disagreement and indifference' (Emmenegger, Schraff, \& Walter, 2014, p. 3), thereby complementing fsQCA's membership gradation. For example, 'neither in nor out' cases correspond with 'indifference' responses. Due to this mapping, fsQCA is utilised in this study.

It is imperative researchers offer full disclosure of their (fs)QCA procedures so that studies are judged against minimum QCA standards (Wagemann et al., 2016). Moreover, as (fs)QCA is relatively new to sport management, a comprehensive overview of our steps taken is provided from a multitude of sources, so as to facilitate QCA's advancement in sport management scholarship. First, as our measures are reflective in nature, it is imperative

\footnotetext{
${ }^{2}$ Multi-value QCA (mvQCA) also exists. However, there is debate surrounding its set-theoretic status. csQCA and fsQCA are also regarded as the main QCA approaches (see e.g. Schneider \& Wagemann, 2013).
} 
discriminant validity and acceptable construct reliabilities are upheld, which we demonstrate through CFA, as per Chang et al. (2013). Next, the 10 ABI dimensions' and PC's test scores should be calibrated, and fuzzy scores created. Calibration is a core activity of QCA (Wagemann et al., 2016), and involves demarcating an entity's qualitatively-different states, which are themselves, potentially important contexts for other conditions (Ragin 2008b). Our calibration procedures followed Leischnig and Kasper-Brauer (2015) and Rauch, Deker, and Woodside (2015). First, we averaged each construct's multi-item measures to create singleitem scores (SISs) for each respondent's ratings (Leischnig \& Kasper-Brauer, 2015). As some SISs were not integers, we considered membership to be (increasingly more) 'out' when SIS was (decreasingly) less than 3.5, (increasingly more) 'in' when SIS was 4.5 or (increasingly) higher, and 'neither in nor out' (the crossover point) when $3.5 \leq$ SIS $<4.5$. Utilising these threshold boundaries allowed us to further distinguish between cases, which is itself an important consideration (see e.g. Chang et al., 2013). Subsequently, we created fuzzy scores by transforming each SIS to fall between 0 and 1, following Rauch et al. (2015), and used the same calibrations for PC and the $10 \mathrm{ABI}$ dimensions.

\section{Necessity}

Once fuzzy scores are created, each simple configuration's necessity is assessed through its consistency, which represents the extent to which a target set is a subset of a configuration. Our target sets are (a) high PC present and (b) high PC absent. It is important to concomitantly investigate high PC's absence because 'the explanation of the absence of the outcome (i.e. the negation of the phenomenon under analysis)...[is not in general] directly derived from the explanation of the presence of the outcome' (Wagemann et al., 2016, p. 2533). 
A simple configuration is considered necessary if its consistency is 0.9 or higher (e.g. Tóth et al., 2015). We find high athlete expertise (consistency score=0.9944), competition style (0.9105), sportsmanship (0.9908), body fit (0.9888), and relationship effort (0.9796), at first glance appear to be simple, necessary solutions for high PC's presence. Moreover, these simple configurations' coverages range from 0.4778 (body fit) to 0.6243 (competition style), indicating they are empirically relevant. However, high athletic expertise (0.9642), sportsmanship (0.9446), body fit, and relationship effort (0.9082) also appear to be simple necessary solutions for high PC's absence. When the same simple necessary configurations appear in both the presence and absence of the same outcome they are considered trivial and removed from further analysis. This is not to say these trivial configurations are unimportant for PC per se, but rather they cannot meaningfully explain differences between high PC's presence and absence in our study (see e.g. Lucidarme et al., 2016). Subsequently, we consider these attributes to be hygiene image attributes (i.e. necessarily needed but not necessarily PC-enhancing). This means only competition style is deemed a simple necessary solution for high PC's presence because it was not a necessary condition for high PC's absence (please see the online supplemental table for all attributes' consistency and coverage scores).

\section{Sufficiency}

Sufficiency should always be assessed after necessity (Wagemann et al., 2016). The first step towards identifying sufficiency is through a truth table (Tóth et al., 2015), which consists of $2^{\mathrm{n}}$ configurations, where $n$ represents the number of unique, simple configurations. Some configurations are found empirically in the data, while others exist logically but lack empirical instances. The latter are called logical remainders, and often occur in empirical studies. 
Next, if simple necessary configurations are found, 'truth table rows (no matter if existing ones or logical remainders) that do not show this condition can be automatically excluded' from further consideration (Wagemann et al., 2016, p. 2535). Relating this to our study, high PC's presence can only meaningfully exist when high competition style is present in truth table rows. Thus, any rows suggesting high competition style's absence leads to high PC (either empirically or through logical remainders) should be removed from the truth table. Following this, researchers must choose an appropriate frequency threshold. This is the minimum level researchers accept configurations are empirically (ir)relevant and is usually based on a study's number of empirical instances (Tóth et al., 2015). We chose a threshold of '2' to increase empirical relevance (Ragin, 2008a). Researchers must also choose an appropriate sufficiency consistency threshold, which now represents the extent to which a configuration is a consistent subset of a target set. A sufficiency consistency threshold should be at least 0.75 or results are too inconsistent (e.g. Ragin, 2008b). We applied Ragin's (2008b) threshold. We note that when we created our truth table for high PC's (a) presence and (b) absence, contradictory truth table rows were found (i.e. the same configurations exist in both truth tables). This is quite normal in applied QCA and can be dealt with at the final analysis stage (e.g. Schneider \& Wagemann, 2013). The truth tables for high PC's presence/absence after necessity, sufficiency and frequency thresholds are accounted for are found in a supplemental table online.

The final stage undertaken before complex sufficient configurations are identified involves logical minimisation using a Boolean Algebra algorithm based on counter-factual analysis. The algorithm removes simple, conflicting configurations from otherwise alike, complex configurations. The minimisation process is informed by both the truth table and scholars' handling of logical remainders. Logical remainders, which are also necessary conditions, are treated as present when a target set is present. Hence, high competition style 
logical remainders are treated as present when high PC exists. Additionally, when 'a cause is necessary for an outcome, then its negation is sufficient for the negation of the outcome' (Ragin, 2000, footnote 4, p. 332). Hence, competition style logical remainders are treated as absent when high PC is absent ${ }^{3}$. Finally, logical remainders of all other ABI attributes are treated as being either present or absent when the target set is present. In this paper, fsQCA 2.5 software (see Ragin, 2008a) is used for counter-factual analysis, which provides complex, intermediate, and parsimonious solutions. The intermediate solution is usually the most interpretable (Ragin, 2008a), not least because necessary conditions are retained during the minimisation process (Ren, Tsai, \& Eisingerich, 2016). We therefore report intermediate solutions.

The solution's overall consistency for high PC's presence is 0.7849 , surpassing Ragin's (2008a) 0.75 threshold. Meanwhile, the overall solution coverage, which 'represents exploratory power and has a meaning similar to R-square values in regression analyses' (Zacharias, Nijssen, \& Stock, 2016, p. 4127), is 0.7146. This indicates the equifinal solutions account for $71.46 \%$ of cases where high PC is present.

High PC exists under three equifinal complex configurations: (a) high competition style's, rivalry's, physical attractiveness's, symbol's, and life story's presence ('High PC Present: Row 1' in Table II); (b) high competition style's, physical attractiveness', symbol's, and role model's presence in conjunction with high rivalry's and life story's absence ('High PC Present: Row 2'); and (c) high competition style's, rivalry's, life story's, and role model's presence in conjunction with high physical attractiveness' and symbol's absence ('High PC

\footnotetext{
${ }^{3}$ Following the logic of Wagemann et al. (2016) and Ragin (2000) we would have removed truth table rows (i.e. before the final analysis stage) contradicting this sufficiency condition for high PC's absence if they had existed empirically. However, whenever empirical cases of competition style's absence occurred, empirical cases of high PC's absence also occurred.
} 
Present: Row 3'). The consistencies of the complex configurations are above 0.75 , meaning they are deemed sufficient configurations (see Table II).

Meanwhile, the overall solution consistency for high PC's absence is 0.8150 , and the overall coverage is 0.7208 . Here, four equifinal complex configurations are found: (a) high rivalry's, physical attractiveness', symbol's, and life story's presence ('High PC Absent: Row 1' in Table II); (b) high physical attractiveness', symbol's, and role model's presence in conjunction with high rivalry's and life story's absence ('High PC Absent: Row 2'); (c) high competition style's, rivalry's, and role model's presence in conjunction with high physical attractiveness' and symbol's absence ('High PC Absent: Row 3'); (d) high rivalry's and life story's presence in conjunction with high competition style's, physical attractiveness', symbol's, and role model's absence ('High PC Absent: Row 4'). The third solution leading to high PC's absence (i.e. 'High PC Absent: Row 3') is regarded as a necessary complex configuration due to its consistency level exceeding 0.9 and its raw coverage exceeding 0.5 (e.g. Mühlbacher et al., 2016). The other three configurations are deemed sufficient complex configurations (see Table II).

\section{TABLE II ABOUT HERE}

\section{FsQCA Overview}

Examining the complex configurations of high PC's presence and absence uncovers vital differences. For example, high competition style is always present when high PC exists (expectedly so given its necessity status). However, when high PC is absent, high competition style may be present, absent or even irrelevant depending upon other ABI attributes it is conjugated with. Similarly, high role model is never absent when high PC exists. Instead, it is present on two occasions and irrelevant on a third occasion. Conversely, high role model's 
absence is found in one complex configuration for low PC. More interesting, a conjugation of high competition style, rivalry, physical attractiveness, symbol, and life story lead to high PC. However, if high competition style is absent from this configuration, high PC is absent. Likewise, high life story forms part of a sufficient configuration for high PC's presence but this dimension is absent from an otherwise exact configuration for high PC's absence. These results suggest subtle differences in complex configurations are the difference between high PC's presence and absence.

\section{General Discussion}

Overall, this study finds ABI's attributes differentially affect PC. Specifically, the SEM analysis shows PC is positively determined by athletic expertise, life story, role model, and competition style, negatively determined by sportsmanship and symbol, and nonsignificantly determined by rivalry, physical attractiveness, body fit, and relationship effort. Meanwhile, the fsQCA analysis demonstrates which ABI attributes are present, absent, irrelevant, or even trivial (hygiene attributes) for high PC. These findings are only noticeable because ABI is operationalised at the dimension-level.

The SEM and fsQCA findings are complementary (Vis, 2012). For example, net of other variables, the on-field attribute, competition style displays a positive relationship with PC, while high competition style is present when high PC is present. Similarly, the off-field attribute, role model is positively related to $\mathrm{PC}$ net of other variables, while high role model is present in two of three configurations (and irrelevant for the other) when high PC exists. Together, these findings generally suggest an athlete needs to be (perceived as) a role model and have a distinct competition style if high PC is to materialise. Furthermore, if these two attributes are considered alongside athletic expertise and life story (both of which were 
significantly related to PC during SEM but trivially linked to high PC during fsQCA), the two analyses findings suggest a combination of these on-field and off-field attributes have at least some importance for (increasingly) high PC towards athlete brands.

Conversely, and given sportsmanship is negatively related to PC net of other variables (SEM) and high sportsmanship is trivially present when high PC exists (fsQCA), it appears individual athletes are expected to have a high baseline level of sportsmanship. Indeed, the manifest variables' mean for sportsmanship's was 6.271. Even so, the negative association between sportsmanship and PC is still somewhat surprising. Perhaps this relationship arises from people's patriotism which is particularly salient during Olympic Games periods. Stated differently, once other ABI attributes are accounted for, perhaps people slightly prefer athletes with 'winning at all costs' mentalities relative to 'wholehearted sportsmanship' mentalities, despite what they may openly express in person. Patriotism may also explain why symbol was negatively linked to PC. For example, some people may believe Olympians should focus their efforts on winning medals rather than wasting time being symbol icons. Indeed, this belief may be especially true for UK Olympic medallists/medal hopefuls given they receive public funding. While we can only speculate on these relationships - particularly given investigations into people's perceptions of these newly-identified image attributes are limited - that we found them reinforces the importance of operationalising $\mathrm{ABI}$ at the dimension-level.

\section{Managerial Implications}

Together, the knowledge generated through SEM and fsQCA can help practitioners (e.g. athletes, agencies, and brand managers) become more efficient when directing resources towards improving (perceptions of) athletes' image attributes, thereby more effectively 
capitalising on athletes' images. Specifically, the findings suggest practitioners should focus resources on respective $\mathrm{ABI}$ attributes that substantially enhance PC. In particular, the results indicate athlete brand managers should try to influence people's perceptions of athletes' distinct competition styles (an 'on-field' attribute). Concurrently, managers should complement this by exploring other ABI attributes athletes are currently most associated with, and then cross-reference these with the ABI configurations that lead to high PC's presence. Incongruities between athletes' perceived attributes and attributes found in the equifinal configurations (Table II) can then be targeted. For example, if people perceive an athlete has no competition style, role model, physical attractiveness, and symbol yet possesses high levels of all other attributes (i.e. 'High PC Absent: Row 4'), resources should only be directed towards enhancing and/or communicating the athlete's competition style and role model. High levels of these two attributes should convert people to high PC, despite physical attractiveness and symbol remaining absent (i.e. 'High PC Present: Row 3'). Indeed, assuming all other ABI attributes remain stable, further increases in an athlete's competition style and role model ought to generate even higher PC, given these attributes were also significant explanatory factors of PC (i.e. SEM). Subsequently, a higher marketing value (e.g. greater fanbase, and more lucrative endorsement opportunities) should follow. Similarly, if people perceive an athlete lacks physical attractiveness and symbol and consider their life story irrelevant, while simultaneously perceiving high levels of all other attributes exist (High PC Absent: Row 3), a natural and instinctive managerial decision may be to improve people's physical attractiveness and symbol perceptions. However, managers would be advised to concentrate solely on making the athlete's life story relevant - not only should high PC materialise (i.e. High PC Present: Row 3) but PC should continue to increase as life story does. 


\section{Theoretical Contributions}

This study makes two primary theoretical contributions to sport management. Additionally, the use of both SEM and fsQCA techniques together provide a deeper and more-rounded understanding of ABI's effect on PC.

First, most ABI literature operationalises 'image' at the higher-order, construct-level (e.g. Arai et al. 2013). Our results highlight the benefits gained from operationalising the construct at the dimension-level. In particular, our theoretical contribution lies in demonstrating how some $\mathrm{ABI}$ dimensions are positively related to $\mathrm{PC}$ while others are negatively or nonsignificantly related. Further, and unlike team-based contexts (e.g. Bauer et al., 2008), we find some off-field attributes (in this case relationship effort, body fit, and physical attractiveness) are not important for PC net of other attributes' contributions, while symbol appears to be negatively impactful. Finally, we demonstrate that numerous ABI pathstrengths to PC are significantly different from one another. These findings are not apparent if $\mathrm{ABI}$ is operationalised at the construct-level. Hence, the study's results support recent measurement theory contentions that higher-order, multidimensional constructs should be examined at the dimension-level (e.g. Lee \& Cadogan, 2013). Hence, scholars should - as a minimum - consider operationalising constructs such as ABI at the dimension-level.

Our second theoretical contribution lies in fsQCA's utilisation within ABI contexts. Here, we find high PC occurs with three equifinal sufficient complex ABI configurations, but is absent when three equifinal sufficient complex configurations, and one necessary complex configuration, exist. Moreover, all ABI attributes play some role for high PC's existence in at least one configuration, whether that be trivially (athletic expertise, sportsmanship, body fit, relationship effort) or differentially (competition style, rivalry, physical attractiveness, symbol, life story, role model). Further, some ABI dimensions experience contrarian 
conditions (i.e. the dimension is present in one complex configuration but absent in another). Hence, the findings adhere to Greckhamer et al.'s (2008) assertions that multiple causes of an outcome exist, individual causes rarely operate in isolation, and some causes may have opposing effects depending upon their respective conjugation.

Finally, by looking at both SEM and (fs)QCA results together, the findings suggest deeper insights are gained when both analysis techniques are used (Vis, 2012). That is, SEM helps scholars analyse how two or more independent variables affect an outcome while QCA informs scholars about intersections among the same independent variables that lead to the same outcome (Urueña \& Hidalgo, 2016). Specifically, in addition to understanding which ABI dimensions are significant explanatory factors of PC (i.e. SEM), scholars can further understand which (non)significant antecedent conditions may still be important when analysed in conjunction with other antecedents (i.e. QCA). Conversely, had other regression models been analysed alongside SEM it is unlikely few if any further insights would emerge. To demonstrate this we reanalysed our data using (a) binary logistic regression (bLR) to mimic conditions' presence/absence, and (b) multinomial logistic regression (mLR) to conceptually at least - mimic fsQCA's gradation (with our 'crossover point' acting as the baseline category). The bLR analysis suggests significantly more variance is explained than when no predictors are included $\left[\Delta \chi^{2}(10)=41.234, p<.001 ; \mathrm{R}^{2}=.189\right.$ (Cox \& Snell), .264 (Nagelkerke)]. Subsequently, the individual parameter estimates suggest role model $(b=.478$, $p=.018$, Odds Ratio $=1.613)$ and life story $(b=.385, p=.008$, Odds Ratio=1.469) significantly predict high PC. Meanwhile, including the ten ABI dimensions in the mLR model resulted in significantly more variance explained than in the baseline model $\left[\Delta \chi^{2}(20)=78.209, p<.001\right.$; $\mathrm{R}^{2}=.328$ (Cox \& Snell), .369 (Nagelkerke)], and the Pearson $(p=.728)$ and Deviance $(p=.754)$ statistics were nonsignificant. Subsequently, the individual parameter estimates suggest sportsmanship $(b=.874, p=.014$, Odds Ratio=2.396) significantly predicts high $\mathrm{PC}$, while role 
model $(b=.441, p=.054$, Odds Ratio $=1.555)$ is marginally significant. Conversely, expertise ( $b=-.684, p=.048$, Odds Ratio=.505), sportsmanship $(b=.926, p=.003$, Odds Ratio=2.524), relationship effort $(b=-.658, p=.009$, Odds Ratio $=.518)$, and life story $(b=-.641, p=.001$, Odds Ratio=.527) are significant predictors of high PC's absence.

We argue these results provide few - if any - additional insights compared to our fsQCA findings, not least because they tell us little about how combinations of nonsignificantly-related ABI attributes could produce high PC. In fact, the bLR results simply offer two significant predictors that were already found to be significant through SEM (i.e. role model and life story). Meanwhile, some mLR findings (e.g. expertise, life story) contradict our SEM results. Hence, both practitioners and scholars would be left wondering which direction to follow if SEM's and mLR's results were to be followed. Instead, (fs)QCA provides 'theoretically, empirically, and substantively highly informative' findings even if nonsignificant findings materialise from regression analyses (Grofman \& Schneider, 2009, p. $666)^{4}$.

\section{Limitations and Future Research}

As with any study, a number of limitations exist. Building upon these will generate further knowledge in this area and begin the inductive process towards external validity. First, we used successful double-Olympians in our study. While this likely increases ecological validity, it may also reduce the dispersion of on-field attributes, such as athletic expertise and sportsmanship. Consequently, future research should consider using up-and-coming or close-

\footnotetext{
${ }^{4} \mathrm{We}$ also reanalysed the data through bLR and mLR using only the ABI dimensions and the associated secondorder interactions retained in the final fsQCA stage. For bLR, few significant predictors were found and some odds ratios appeared implausibly high. Similarly, few significant relationships were found in mLR and some odds ratios were questionable. This demonstrates the high demands placed on data when so many interactions are considered (Schneider \& Wagemann, 2013). We do not report these results because we would only really know which ABI dimensions to include in the logistics regression models $\underline{\text { after }}$ fsQCA was undertaken (even with painstakingly looking for parsimony). In turn, this strengthens our view that fsQCA and SEM are complementary.
} 
to-retiring athletes, and/or athletes with known unsportsmanlike behaviour. Second, following Arai and colleagues, we focused on ABI's attributes and PC. However, respondents' individual differences may also be important (i.e. boundary conditions). For example, a competitive person might embrace athletes' rivalries but an uncompetitive person might prefer athletes who display fellowship. Third, we measured ABI's dimensions using reflective indicators, following measurement theory. However, it could be argued that Arai and colleagues measured some of their dimensions in a formative manner (e.g. competition style). If some original $\mathrm{ABI}$ dimensions are formative in nature they would contain subdimensions, and these could be captured using reflective indicators too. We did not go to this sub-dimension level because we wanted to minimise respondent fatigue, and believe our reflective items appropriately capture the ABI definitions. Moreover, we suggest our findings are more robust and interpretable at the dimension-level compared to the sub-dimensionlevel, which substantially increases the number of conditions (see Wagemann et al., 2016). However, future research may consider balancing these issues against the potential knowledge generated from measuring ABI's sub-dimensions. Finally, we used 7-point Likerttype scales, which complements fsQCA's gradation membership (Emmenegger et al., 2014). However, Likert-type scales cannot capture aetiological antecedents of individuals' ratings. Further, we could not triangulate specific individual's responses with in-depth case analysis because we followed Podsakoff et al.'s (2003) recommendation of respondent anonymity for response-rate enhancement. Hence, while our QCA technique is perfectly acceptable (see e.g. Wagemann et al., 2016), future studies may consider combining qualitative and quantitative data, either to triangulate findings, or as an alternative approach to uncovering respective conditions. For example, qualitative interviews informed Winand et al.'s (2013) choice of simple configurations while quantitative data informed their performance outcome. Similarly, Clausen et al. (2018) used financial statements to inform their outcome-choice while simple 
configurations were deduced from triangulating literature, documents, and interviews. That said, in studies such as ours, researchers must avoid activating socially desirable responses if they are also collecting qualitative data as this could mask otherwise unexpected findings, which then lead to future research questions (e.g. in our study, 'why is sportsmanship's relationship with PC negative?'). More broadly, the pragmatic scholar who utilises regression-based and QCA-based techniques must carefully balance each approach's respective epistemological foundations in future studies. 


\section{References}

Arai, A., Ko, Y. J., \& Kaplanidou, K. (2013). Athlete brand image: scale development and model test. European Sport Management Quarterly, 13, 383-403.

Arai, A., Ko, Y. J., \& Ross, S. (2014). Branding athletes: Exploration and conceptualization of athlete brand image. Sport Management Review, 17, 97-106.

Bachleda, C., Fakhar, A., \& Elouazzani, Z. (2016). Quantifying the effect of sponsor awareness and image on the sports involvement-purchase intention relationship. Sport Management Review, 19, 293-305.

Bauer, H. H., Stokburger-Sauer, N. E., \& Exler, S. (2008). Brand image and fan loyalty in professional team sport: A refined model and empirical assessment. Journal of Sport Management, 22, 205-226.

Bee, C. C., \& Havitz, M. E. (2010). Exploring the relationship between involvement, fan attraction, psychological commitment and behavioural loyalty in a sports spectator context. International Journal of Sports Marketing and Sponsorship, 11(2), 37-54.

Braunstein, J. R., \& Zhang, J. J. (2005). Dimensions of athletic star power associated with Generation Y sports consumption. International Journal of Sports Marketing and Sponsorship, 6(4), 37-62.

Bush, A. J., Martin, C. A., \& Bush, V. D. (2004). Sports celebrity influence on the behavioral intentions of generation Y. Journal of Advertising Research, 44, 108-118.

Cadogan, J. W., Lee, N., Tarkiainen, A., \& Sundqvist, S. (2009). Sales manager and sales team determinants of salesperson ethical behaviour. European Journal of Marketing, 43, 907-937. 
Carlson, B. D., \& Donavan, D. T. (2013). Human brands in sport: Athlete brand personality and identification. Journal of Sport Management, 27, 193-206.

Chang, C. W., Tseng, T. H., \& G. Woodside, A. (2013). Configural algorithms of patient satisfaction, participation in diagnostics, and treatment decisions' influences on hospital loyalty. Journal of Services Marketing, 27, 91-103.

Clausen, J., Bayle, E., Giauque, D., Ruoranen, K., Lang, G., Schlesinger, T., Klenk, C., \& Nagel, S. (2018). International sport federations' commercialisation: a qualitative comparative analysis. European Sport Management Quarterly, 18, 373-392.

Edwards, J. R. (2011). The fallacy of formative measurement. Organizational Research Methods, 14, 370-388.

Emmenegger, P., Schraff, D., \& Walter, A. (2014). QCA, the truth table analysis and large- $n$ survey data: The benefits of calibration and the importance of robustness tests. Presented at II. Zürich: International QCA Expert Workshop.

Fornell, C., \& Larcker, D. F. (1981). Evaluating Structural Equation Models with unobservable variables and measurement error. Journal of Marketing Research, 18, 3950.

Gladden, J. M., \& Funk, D. C. (2001). Understanding brand loyalty in professional sport: Examining the link between brand associations and brand loyalty. International Journal of Sports Marketing and Sponsorship, 3(1), 54-81.

Gladden, J. M., \& Funk, D. C. (2002). Developing an understanding of brand associations in team sport: Empirical evidence from consumers of professional sport. Journal of Sport Management, 16, 54-81. 
Greckhamer, T., Misangyi, V. F., Elms, H., and Lacey, R. (2008). Using QCA in Strategic Management Research: An Examination of Combinations of Industry, Corporate, and Business Unit Effects. Organizational Research Methods, 11, 695-726.

Grofman, B., \& Schneider, C. Q. (2009). An introduction to crisp set QCA, with a comparison to binary logistic regression. Political Research Quarterly, 62, 662-672.

Hodge, C., \& Walker, M. (2015). Personal branding: a perspective from the professional athlete-level-of-analysis. International Journal of Sport Management and Marketing, 16, 112-131.

Hui, C. H., \& Triandis, H. C. (1985). Measurement in cross-cultural psychology: A review and comparison of strategies. Journal of Cross-Cultural Psychology, 16, 131-152.

Inoue, Y., Funk, D. C., \& McDonald, H. (2017). Predicting behavioral loyalty through corporate social responsibility: The mediating role of involvement and commitment. Journal of Business Research, 75, 46-56.

Iwasaki, Y., \& Havitz, M. E. (2004). Examining relationships between leisure involvement, psychological commitment and loyalty to a recreation agency. Journal of Leisure Research, 36, 45-72.

Jarvis, C. B., MacKenzie, S. B., \& Podsakoff, P. M. (2003). A critical review of construct indicators and measurement model misspecification in marketing and consumer research. Journal of Consumer Research, 30, 199-218.

Kilduff, G. J., Elfenbein, H. A., \& Staw, B. M. (2010). The psychology of rivalry: A relationally dependent analysis of competition. Academy of Management Journal, 53, 943-969. 
Kim, M., \& Walker, M. (2013). The influence of professional athlete philanthropy on donation intentions. European Sport Management Quarterly, 13, 579-601.

Kunkel, T., Funk, D. C., \& Lock, D. (2017). The Effect of the League Brand on the Relationship Between the Team Brand and Behavioural Intentions: A Formative Approach Examining Brand Associations and Brand Relationships. Journal of Sport Management, 31, 317-332.

Lee, N., \& Cadogan, J. W. (2013). Problems with formative and higher-order reflective variables. Journal of Business Research, 66, 242-247.

Lee, N., \& Chamberlain, L. (2016). Pride and prejudice and causal indicators. Measurement: Interdisciplinary Research and Perspectives, 14, 105-109.

Lee, S. P., Cornwell, T. B., \& Babiak, K. (2012). Developing an instrument to measure the social impact of sport: social capital, collective identities, health literacy, well-being and human capital. Journal of Sport Management, 27, 24-42.

Lee, J. G., \& Park, J. (2014). The effects of endorsement strength and celebrity-product match on the evaluation of a sports-related product: the role of product involvement. International Journal of Sports Marketing and Sponsorship, 16(1), 50-69.

Leischnig, A., \& Kasper-Brauer, K. (2015). Employee adaptive behaviour in service enactments. Journal of Business Research, 68, 273-280.

Lohneiss, A., \& Hill, B. (2014). The impact of processing athlete transgressions on brand image and purchase intent. European Sport Management Quarterly, 14, 171-193.

Lucidarme, S., Cardon, G., \& Willem, A. (2016). A Comparative Study of Health Promotion Networks: Configurations of determinants for network effectiveness. Public Management 
Review, 18, 1163-1217.

MacKenzie, S. B., \& Lutz, R. J. (1989). An empirical examination of the structural antecedents of attitude toward the ad in an advertising pretesting context. Journal of Marketing, 53(2), 48-65.

Mael, F., \& Ashforth, B. E. (1992). Alumni and their alma mater: A partial test of the reformulated model of organizational identification. Journal of Organizational Behavior, $13,103-123$.

Mahony, D. F., Madrigal, R., \& Howard, D. A. (2000). Using the psychological commitment to team (PCT) scale to segment sport consumers based on loyalty. Sport Marketing Quarterly, 9, 15-25.

Markus, K. A., \& Borsboom, D. (2013). Frontiers of test validity theory. New York, NY: Routledge.

Marx, A., \& van Hootegem, G. (2007). Comparative configurational case analysis of ergonomic injuries. Journal of Business Research, 60, 522-530.

McCormick, K. (2018). Impact of athletic star power on product consumption. International Journal of Sports Marketing and Sponsorship, doi: 10.1108/IJSMS-06-2016-0030.

Mühlbacher, H., Raies, K., Grohs, R., \& Koll, O. (2016). Drivers of brand strength: Configural paths to strong cognitive brand equity. Journal of Business Research, 69, 2774-2780.

Netemeyer, R. G., \& Bearden, W. O. (1992). A comparative analysis of two models of behavioral intention. Journal of the Academy of Marketing Science, 20, 49-59.

Park, C. W., Jaworski, B. J., \& MacInnis, D. J. (1986). Strategic brand concept-image 
management. Journal of Marketing, 50(4), 135-145.

Park, C. W., MacInnis, D. J., \& Priester, J. W. (2014). Research Directions on Strong Brand Relationships. D. J. MacInnis, C. W. Park, \& J. W. Priester (Eds.), Handbook of Brand Relationships (pp. 379-393). Oxon: Routledge.

Pifer, N. D., Mak, J. Y., Bae, W. Y., \& Zhang, J. J. (2015). Examining the Relationship Between Star Player Characteristics and Brand Equity in Professional Sport Teams. Marketing Management Journal, 25, 88-106.

Podsakoff, P. M., MacKenzie, S. B., Lee, J. Y., \& Podsakoff, N. P. (2003). Common method biases in behavioral research: a critical review of the literature and recommended remedies. Journal of Applied Psychology, 88, 879-903.

Ragin, C. C. (2000). Fuzzy-set social science. Chicago, IL: University of Chicago Press.

Ragin, C. C. (2008a). User's Guide to Fuzzy-Set/Qualitative Comparative Analysis, 1-87. Retrieved from www.u.arizona.edu/ cragin/fsQCA/download/fsQCAManual.pdf

Ragin, C. C. (2008b). Redesigning social inquiry. Chicago, IL: University of Chicago Press.

Rauch, A., Deker, J. S., \& Woodside, A. G. (2015). Consuming alone: Broadening Putnam's "bowling alone" thesis. Psychology \& Marketing, 32, 967-976.

Ren, S., Tsai, H. T., \& Eisingerich, A. B. (2016). Case-based asymmetric modelling of firms with high versus low outcomes in implementing changes in direction. Journal of Business Research, 69, 500-507.

Ross, S. D. (2007). Segmenting sport fans using brand associations: A cluster analysis. Sport Marketing Quarterly, 16, 15-24.

Ross, S. D., James, J. D., \& Vargas, P. (2006). Development of a scale to measure team brand 
associations in professional sport. Journal of Sport Management, 20, 260-279.

Sassenberg, A. (2015). Effects of sport celebrity transgressions: An exploratory study. Sport Marketing Quarterly, 24, 78-90.

Schneider, C. Q., \& Wagemann, C. (2013). Set-theoretic methods for the social sciences: A guide to Qualitative Comparative Analysis. Cambridge, UK: Cambridge University Press.

Stokburger-Sauer, N., Ratneshwar, S., \& Sen, S. (2012). Drivers of consumer-brand identification. International Journal of Research in Marketing, 29, 406-418.

Stone, G., Joseph, M., \& Jones, M. (2003). An exploratory study on the use of sports celebrities in advertising: A content analysis. Sport Marketing Quarterly, 12, 94-102.

Summers, J., \& Morgan, M. J. (2008). More than just the media: Considering the role of public relations in the creation of sporting celebrity and the management of fan expectations. Public Relations Review, 34, 176-182.

Thomson, M. (2006). Human brands: Investigating antecedents to consumers' strong attachments to celebrities. Journal of Marketing, 70(3), 104-119.

Tokuyama, S., \& Greenwell, T. C. (2011). Examining similarities and differences in consumer motivation for playing and watching soccer. Sport Marketing Quarterly, 20, 148-156.

Tóth, Z., Thiesbrummel, C., Henneberg, S. C., \& Naudé, P. (2015). Understanding configurations of relational attractiveness of the customer firm using fuzzy set QCA. Journal of Business Research, 68, 723-734.

Tsiotsou, R. H., Alexandris, K., \& Bettina Cornwell, T. (2014). Using evaluative conditioning to explain corporate co-branding in the context of sport sponsorship. International 
Journal of Advertising, 33, 295-327.

Urueña, A., \& Hidalgo, A. (2016). Successful loyalty in e-complaints: FsQCA and structural equation modeling analyses. Journal of Business Research, 69, 1384-1389.

Vis, B. (2012). The comparative advantages of fsQCA and regression analysis for moderately large-N analyses. Sociological Methods \& Research, 41, 168-198.

Wagemann, C., Buche, J., \& Siewert, M. B. (2016). QCA and business research: Work in progress or a consolidated agenda? Journal of Business Research, 69, 2531-2540.

Walsh, P., \& Williams, A. (2017). To Extend or Not Extend a Human Brand: An Analysis of Perceived Fit and Attitudes Toward Athlete Brand Extensions. Journal of Sport Management, 31, 44-60.

Williams, L. J., \& O'Boyle, E. (2011). The myth of global fit indices and alternatives for assessing latent variable relations. Organizational Research Methods, 14, 350-369.

Winand, M., Rihoux, B., Robinson, L., \& Zintz, T. (2013). Pathways to high performance: A qualitative comparative analysis of sport governing bodies. Nonprofit and Voluntary Sector Quarterly, 42, 739-762.

Woodside, A. G. (2013). Moving beyond multiple regression analysis to algorithms: Calling for adoption of a paradigm shift from symmetric to asymmetric thinking in data analysis and crafting theory. Journal of Business Research, 66, 463-472.

Woodside, A. G. (2015). Constructing business-to-business marketing models that overcome the limitations in variable-based and case-based research paradigms. Journal of Businessto-Business Marketing, 22, 95-110.

Zacharias, N. A., Nijssen, E. J., \& Stock, R. M. (2016). Effective configurations of value 
creation and capture capabilities: Extending Treacy and Wiersema's value disciplines. Journal of Business Research, 69, 4121-4131. 


\begin{tabular}{|c|c|c|}
\hline Items and sources & $\begin{array}{c}\text { Completely } \\
\text { standardised } \\
\text { loadings } \\
\end{array}$ & $\begin{array}{c}\text { Error } \\
\text { variances }\end{array}$ \\
\hline \multicolumn{3}{|l|}{$\begin{array}{l}\text { Athletic Expertise (Arai et al., 2013; Netemeyer \& Bearden, 1992) } \\
\overline{\mathrm{x}}(\sigma)=6.602(0.736)\end{array}$} \\
\hline $\begin{array}{l}\text { When I think about the athlete's expertise in their sport, the athlete is... } \\
\text {...very knowledgeable in their sport } \\
\text {... an expert in their sport } \\
\text {... accomplished in their sport }\end{array}$ & $\begin{array}{l}.719 \\
.940 \\
.694\end{array}$ & $\begin{array}{l}.483 \\
.116 \\
.518\end{array}$ \\
\hline \multicolumn{3}{|l|}{$\begin{array}{l}\text { Competition Style (Arai et al., 2013; Carlson \& Donavan, 2013) } \\
\overline{\mathrm{x}}(\sigma)=4.956(1.132)\end{array}$} \\
\hline $\begin{array}{l}\text { The athlete's competition style is distinctive from other players } \\
\text { The athlete is unique compared with other athletes } \\
\text { The athlete has unique competitive skills }\end{array}$ & $\begin{array}{l}.760 \\
.710 \\
.811\end{array}$ & $\begin{array}{l}.422 \\
.496 \\
.342\end{array}$ \\
\hline \multicolumn{3}{|l|}{$\begin{array}{l}\text { Rivalry (Ross et al., 2006; Kilduff et al., 2010; Mael \& Ashforth, 1992) } \\
\overline{\mathrm{x}}(\sigma)=4.841(1.400)\end{array}$} \\
\hline $\begin{array}{l}\text { When this person competes I think... } \\
\text {...they see their fellow competitors as big rivals } \\
\text {...there is intensive rivalry between this athlete and their competitors } \\
\text {...they see their fellow competitors as big enemies }\end{array}$ & $\begin{array}{l}.741 \\
.853 \\
.653\end{array}$ & $\begin{array}{l}.451 \\
.272 \\
.573\end{array}$ \\
\hline \multicolumn{3}{|l|}{$\begin{array}{l}\text { Sportsmanship (Arai et al., 2013) } \\
\overline{\mathrm{x}}(\sigma)=6.271(0.929)\end{array}$} \\
\hline $\begin{array}{l}\text { When I think about sportsmanship, the athlete shows... } \\
\text {...sportsmanship in competition } \\
\text {...respect for their fellow sports competitors } \\
\text {...fair play }\end{array}$ & $\begin{array}{l}.790 \\
.878 \\
.878\end{array}$ & $\begin{array}{l}.376 \\
.229 \\
.229\end{array}$ \\
\hline \multicolumn{3}{|l|}{$\begin{array}{l}\text { Physical Attractiveness (Arai et al., 2013) } \\
\overline{\mathrm{x}}(\sigma)=4.250(1.535)\end{array}$} \\
\hline $\begin{array}{l}\text { The athlete is physically attractive } \\
\text { The athlete is physically good looking } \\
\text { Physically the athlete is beautiful }\end{array}$ & $\begin{array}{l}.940 \\
.887 \\
.838\end{array}$ & $\begin{array}{l}.116 \\
.213 \\
.298\end{array}$ \\
\hline \multicolumn{3}{|l|}{$\begin{array}{l}\text { Symbol (Arai et al., 2013) } \\
\overline{\mathrm{x}}(\sigma)=3.937(1.252)\end{array}$} \\
\hline $\begin{array}{l}\text { I imagine the athlete's private fashion (i.e. outside of when they } \\
\text { compete) to be... } \\
\text {...trendy } \\
\text {...stylish } \\
\text {..."in vogue" }\end{array}$ & $\begin{array}{l}.880 \\
.952 \\
.634\end{array}$ & $\begin{array}{l}.225 \\
.095 \\
.598\end{array}$ \\
\hline \multicolumn{3}{|l|}{$\begin{array}{l}\text { Body Fit (Arai et al., 2013; Braunstein \& Zhang, 2005) } \\
\bar{x}(\sigma)=6.618(0.753)\end{array}$} \\
\hline $\begin{array}{l}\text { When I think of the physical fitness levels needed to compete at an } \\
\text { elite level in this athlete's sport, I would say the... } \\
\text {...athlete is in good shape } \\
\text {... athlete is physically fit } \\
\text {...athlete's body is well conditioned }\end{array}$ & $\begin{array}{l}.948 \\
.928 \\
.879\end{array}$ & $\begin{array}{l}.101 \\
.139 \\
.228\end{array}$ \\
\hline \multirow{2}{*}{\multicolumn{3}{|c|}{$\begin{array}{l}\text { Life Story (Arai et al., 2013; Braunstein \& Zhang, 2005) } \\
\overline{\mathrm{x}}(\sigma)=3.919(1.349)\end{array}$}} \\
\hline & .722 & .478 \\
\hline
\end{tabular}




\begin{tabular}{|c|c|c|}
\hline $\begin{array}{l}\text { interesting to follow } \\
\text { This athlete's personal life is interesting to follow } \\
\text { This athlete's personal life increases interest in them }\end{array}$ & $\begin{array}{l}.847 \\
.681\end{array}$ & $\begin{array}{l}.282 \\
.537\end{array}$ \\
\hline \multicolumn{3}{|l|}{$\begin{array}{l}\text { Role Model }^{*} \text { (Cadogan et al., 2009) } \\
\overline{\mathrm{x}}(\sigma)=5.368(1.070)\end{array}$} \\
\hline $\begin{array}{l}\text { This athlete shows good ethical standards in society } \\
\text { Being ethical in society is important for this athlete }\end{array}$ & $\begin{array}{l}.943 \\
.563 \\
\end{array}$ & .110 \\
\hline \multicolumn{3}{|l|}{$\begin{array}{l}\text { Relationship Effort (MacKenzie \& Lutz, 1989) } \\
\overline{\mathrm{x}}(\sigma)=6.014(1.070)\end{array}$} \\
\hline $\begin{array}{l}\text { When this athlete interacts with fans, their attitude appears... } \\
\text {...positive } \\
\text {...good } \\
\text {...favourable }\end{array}$ & $\begin{array}{l}.928 \\
.952 \\
.903 \\
\end{array}$ & $\begin{array}{l}.139 \\
.093 \\
.185 \\
\end{array}$ \\
\hline \multicolumn{3}{|l|}{$\begin{array}{l}\text { Psychological Commitment (Stokburger-Sauer et al., 2012) } \\
\bar{x}(\sigma)=3.702(1.565)\end{array}$} \\
\hline $\begin{array}{l}\text { I am very fond of this athlete } \\
\text { I am very committed to this athlete } \\
\text { I consider myself to be very loyal to this athlete }\end{array}$ & $\begin{array}{l}.750 \\
.903 \\
.916\end{array}$ & $\begin{array}{l}.438 \\
.184 \\
.161\end{array}$ \\
\hline
\end{tabular}

All variables used fully-labelled 7-point Likert-type scales (anchored 'Strongly Disagree'/‘Strongly Agree)

* two indicators are perfectly acceptable for this study (see e.g. Lee, Cornwell, \& Babiak, 2012) 


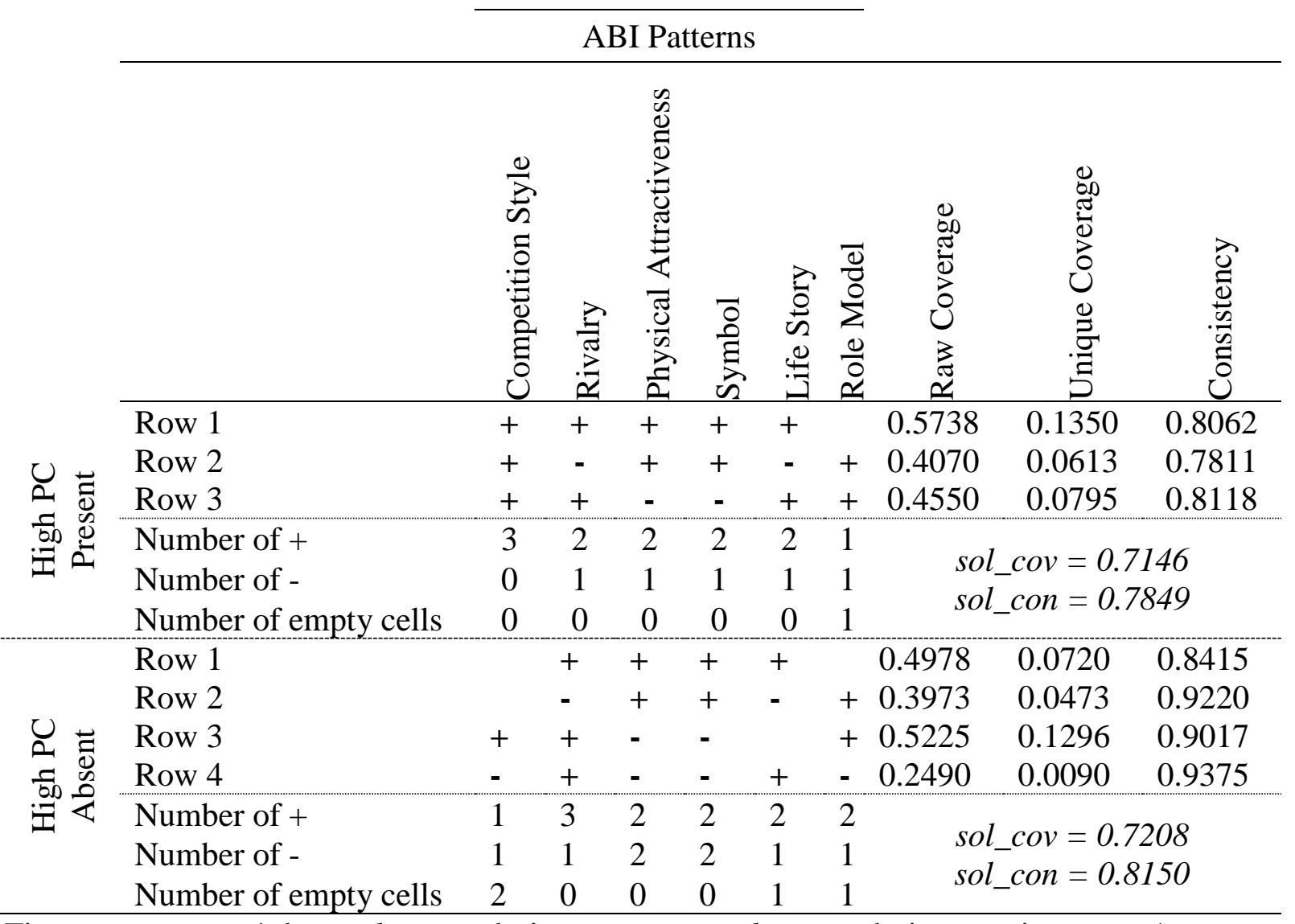

Figures correct to 4 d.p.; sol_cov=solution coverage; sol_con=solution consistency; +/indicates presence/absence of high (levels of) attribute; empty cells indicate simple irrelevant conditions. 


\section{Figure I:Conceptual Framework}

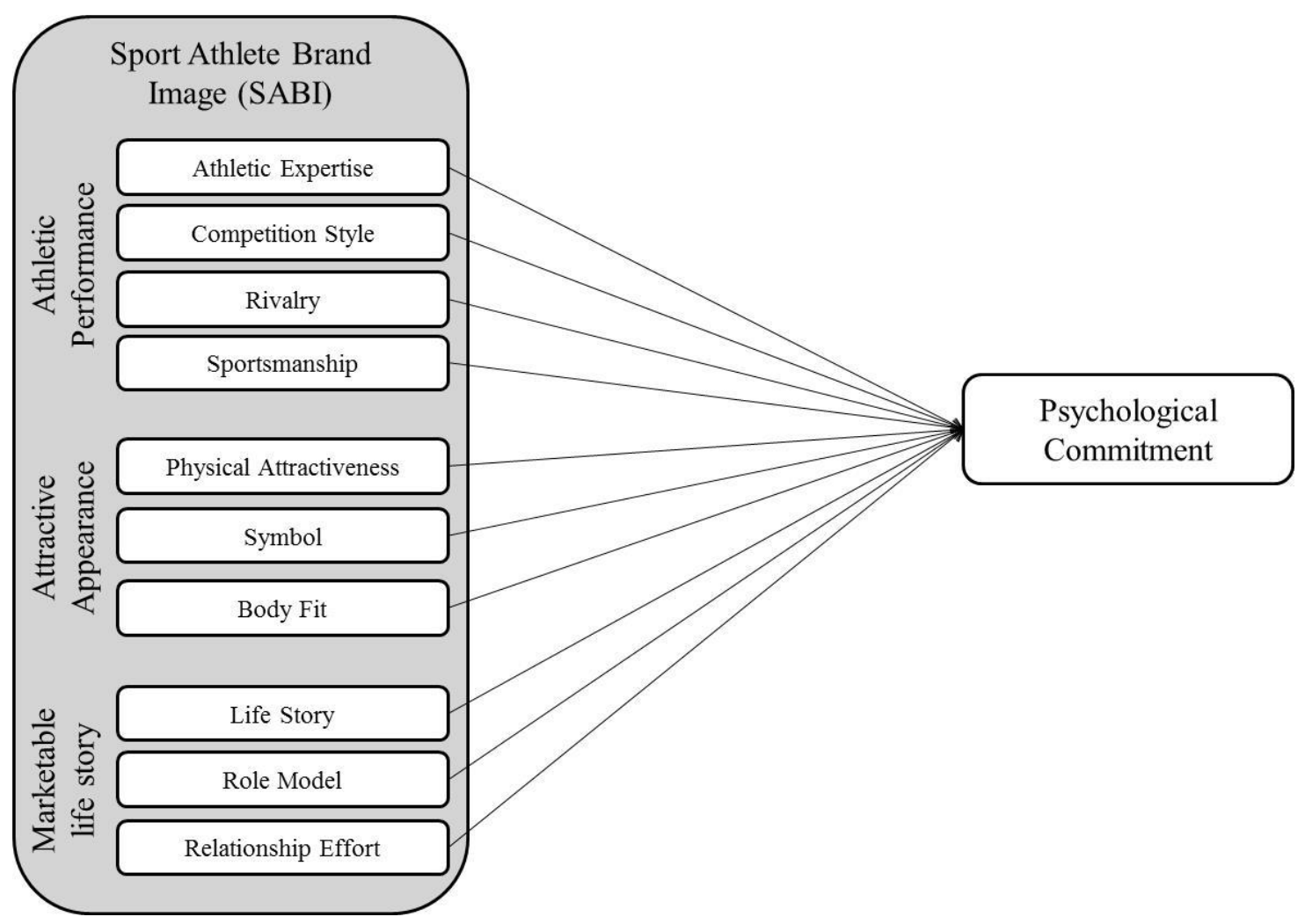

